\section{High-definition endoscopy with i-scan enables diagnosis of characteristic mucosal lesions in Whipple's disease}

Whipple's disease is a rare multisystemic chronic bacterial infection caused by Tropheryma whipplei, which can involve the gastrointestinal, nervous, and cardiac systems and skin. Clinical presentation and laboratory findings are often variable and depend on the major organs involved, and this can hamper establishing the final diagnosis of Whipple's disease [1]. Histopathological examination using periodic acid-Schiff (PAS) stain demonstrates PASpositive sickle particles within cells (SPC), which are characteristic of the disease [1]. Previous endoscopic studies using highresolution endoscopes have already high- lighted the potential of optical magnification endoscopy and optical chromoendoscopy using narrow band imaging for diagnosis of Whipple's disease-specific mucosal alterations [2,3]. Moreover, ultrastructural findings in Whipple's disease, using fluorescein-aided confocal laser endomicroscopy, have also been reported $[4,5]$. To date, no data are available on the utility of high-definition white-light endoscopy or virtual chromoendoscopy in the characterization of Whipple's disease.

A 45-year-old man presented with chronic diarrhea, malaise, and unspecific abdominal discomfort. Physical examination was unremarkable, while laboratory tests demonstrated signs of systemic inflammation (white blood cell count $18.2 \times 10^{9} / \mathrm{L}$ reference $4-10 \times 10^{9} / \mathrm{L}$, C-reactive protein $84 \mathrm{mg} / \mathrm{L}$, reference $<5 \mathrm{mg} / \mathrm{L}$ ) and normocytic anemia (hemoglobin $8.2 \mathrm{~g} / \mathrm{dL}$, reference $12-16 \mathrm{~g} / \mathrm{dL}$ ). High-definition whitelight endoscopy revealed pale yellow, shaggy mucosa with intermittent, superficial, erythematous eroded patches of the duodenum ( $\bullet$ Fig. 1 a). Virtual chromoendoscopy with i-Scan (Pentax, Tokyo, Japan) additionally revealed edematous and engorged duodenal villi filled with a white material representing lymph. Concentric rings of the mucosa were also visible, which have been identified to be specific for Whipple's disease in previous studies using optical magnification endoscopy and 115-fold magnification ( Fig.1 b,c) [5]. The diagnosis of Whipple's disease was confirmed by multiple PAS-positive macrophages in the lamina propria and
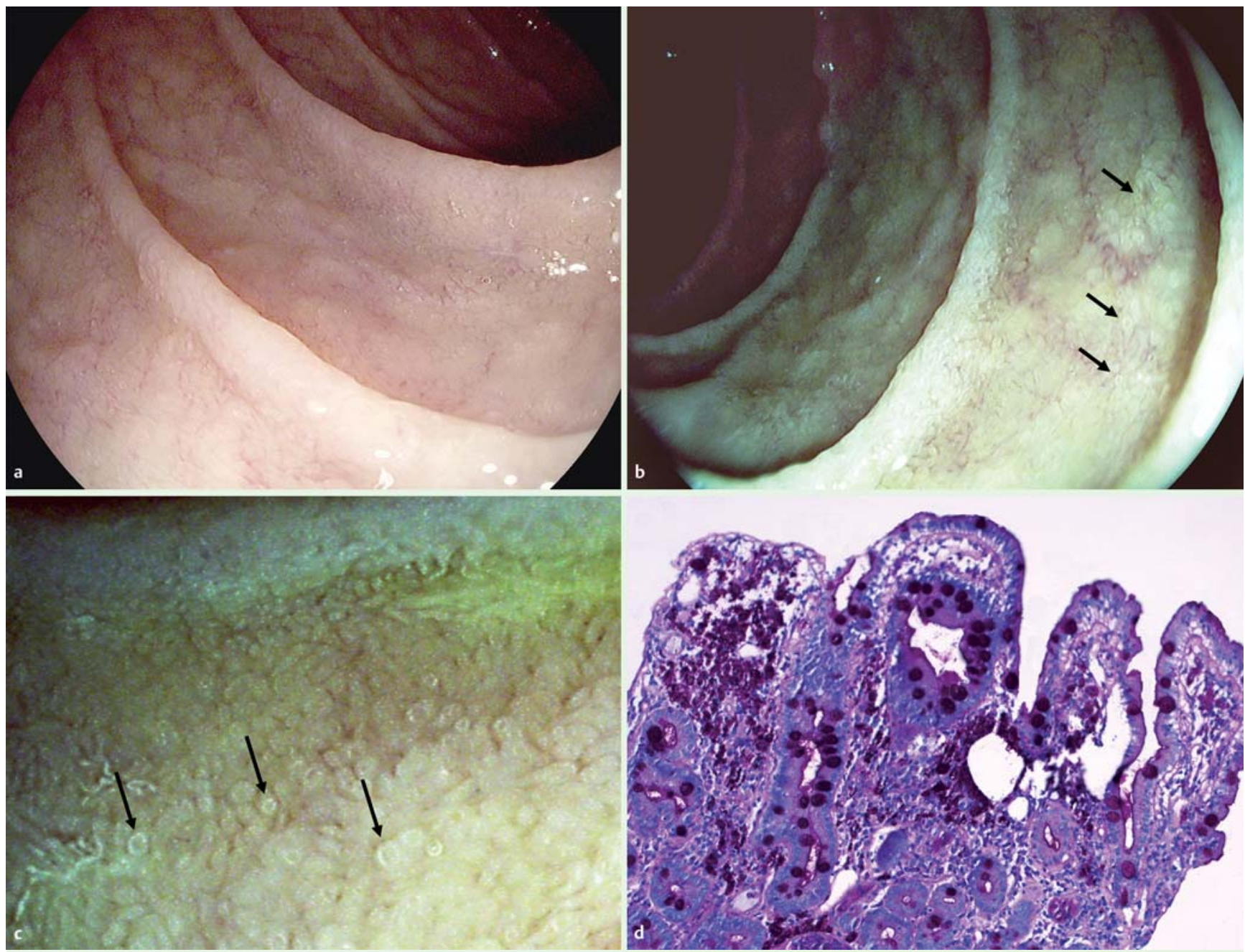

Fig. 1 a High-definition white-light endoscopy in a 45-year-old man with Whipple's disease demonstrating slightly flattened, engorged duodenal villi. b, c Importantly, virtual chromoendoscopy with i-scan showing white-yellowish concentric rings inside the villi (arrows; magnified image in c). $\mathbf{d}$ Corresponding PAS staining of duodenal biopsy samples revealed multiple macrophages in the lamina propria. 
polymerase chain reaction (PCR) analysis of tissue biopsies positive for $T$. whipplei ( Fig.1d). The patient was treated for 2 weeks with intravenous ceftriaxone, followed by trimethoprim/sulfamethoxazole for 12 months, resulting in significant improvement in symptoms.

Our case is of interest, as this is the first time Whipple's disease has been characterized by using advanced endoscopic imaging with high-definition white-light endoscopy and virtual chromoendoscopy (i-scan, Pentax, tokyo, Japan). With this approach, we were able to easily identify mucosal alterations characteristic for Whipple's disease which have been previously reported to be visible only with optical magnification endoscopy [6]. Therefore, advanced endoscopic imaging using virtual chromoendoscopy allows better characterization of mucosal alterations in Whipple's disease, which may therefore improve endoscopic diagnosis. This would further allow targeted biopsy sample acquisition, and the histopathological findings may help confirm the diagnosis of Whipple's disease in the early stages of the disease, thus improving patient outcome.
Importantly, the endoscopist has to be aware of this rare but still present multisystemic chronic bacterial infection and should always proceed with careful inspection and acquisition of biopsy specimens of duodenal mucosa in patients with intestinal (i.e., diarrhea) or extraintestinal symptoms (i.e., joint pain, pericarditis) suggestive of Whipple's disease.

Endoscopy_UCTN_Code_CCL_1AB_2AZ_3AC

\section{Competing interests: None}

\section{H. Neumann ${ }^{1}$, C. Neufert ${ }^{1}$, M. Vieth ${ }^{2}$, J. Siebler ${ }^{1}$, K. Mönkemüller ${ }^{3}$, \\ M. F. Neurath ${ }^{1}$}

${ }^{1}$ Department of Medicine I, University of Erlangen-Nürnberg, Erlangen, Germany

${ }^{2}$ Institute of Pathology, Klinikum Bayreuth, Germany

${ }^{3}$ Department of Internal Medicine and Gastroenterology, Marienhospital Bottrop, Bottrop, Germany

\section{References}

1 Fenollar F, Puéchal X, Raoult D. Whipple's disease. N Engl J Med 2007; 356: 55 - 66

2 Neumann $H$, Mönkemüller $K$, Malfertheiner $P$. Whipple's disease. Clin Gastroenterol Hepatol 2008; 6: 08A32

3 Neumann $H$, Mönkemüller $K$, Vieth $M$ et al. Advanced endoscopic imaging using narrow band imaging for diagnosis of Whipple's disease. Endoscopy 2012: [in press]

4 Neufert C, Vieth M, Mönkemüller $K$ et al. In vivo diagnosis and characterisation of Whipple's disease. Lancet Infect Dis 2011; 11: 970

5 Dolak W, Leitner J, Maresch J et al. In vivo identification by confocal laser endoscopy of foamy macrophages associated with Whipple's disease. Endoscopy 2010; 42: 310-311

6 Mönkemüller K, Fry LC, von Arnim U et al. Whipple's disease: an endoscopic and histologic study. Digestion 2008; 77: 161 - 165

\section{Bibliography}

Dol http://dx.doi.org/

10.1055/s-0032-1309357

Endoscopy 2012; 44: E217-E218

(c) Georg Thieme Verlag KG

Stuttgart · New York

ISSN 0013-726X

Corresponding author

Professor H. Neumann

Department of Medicine I

University of Erlangen-Nuremberg

Ulmenweg 18

91054 Erlangen

Germany

Fax: +49-9131-85-35209

helmut.neumann@uk-erlangen.de 